\title{
Call for Candidates: Managing Editor for the Americas Pediatric Radiology
}

Published online: 8 February 2022

(c) Springer-Verlag GmbH Germany, part of Springer Nature 2022

The Society for Pediatric Radiology and the publisher Springer are seeking applications and nominations for the position of the Managing Editor for the Americas at the journal Pediatric Radiology.

Pediatric Radiology is the official journal of the Society for Pediatric Radiology (SPR), the European Society of Paediatric Radiology (ESPR), the Asian and Oceanic Society for Pediatric Radiology (AOSPR) and the Sociedad Latinoamericana de Radiología Pediátrica (SLARP). The journal is the only journal dedicated exclusively to the subspecialty of pediatric radiology and a primary source of information to the international community of pediatric radiologists.

The journal receives submissions on all aspects of pediatric radiology from all over the world and publishes scientific articles and review articles on timely topics. The journal is under the leadership of two Managing Editors, one from the USA affiliated with the SPR and one from Europe affiliated with the ESPR. A close working relationship between the two Managing Editors is indispensable for the success of the journal. The US Managing Editor, working in consultation with Assistant Editors, is responsible for manuscripts submitted from the Americas. The two Managing Editors account for the content of the journal. This includes acquiring, reviewing and collating manuscripts for publication in a timely manner as well as corresponding with the Editorial Board, reviewers and authors. In addition, the Managing Editors arrange special issues on topics of interest to the international community of pediatric radiologists. Furthermore, the Managing Editors appoint the Editorial Board. The Managing Editors adhere to standards of good editorial practice and the publisher's code of conduct.

The US Managing Editor serves a 5-year term. The term of service for this position starts on January 1st, 2023 and expires on December 31st, 2027. We plan for a hand-over transition period starting on September 1st, 2022.

The ideal candidate should have a vision of how to lead the journal and increase its impact in the international community, as well as the desire to continue a close working relationship with his/her European colleagues. The candidate should have a broad interest and experience in pediatric radiology and research, a commitment to leading this journal to a preeminent position in the specialty, and a clear idea of the pragmatic issues involved in accomplishing this mission. Successful applicants must have experience as an editor, associate editor or productive editorial board member of a peer-reviewed journal.

The new US Managing Editor will be appointed by Springer in consultation and agreement with the SPR. The US Managing Editor is expected to work closely with the global publisher Springer on all aspects of publishing, to be an active member of the SPR and to liaise with the SPR leadership and the membership-at-large.

Each interested individual is invited to submit an application via e-mail. The application should include: a succinct letter of interest and qualifications, a vision statement and short curriculum vitae.

Contact for queries and applications:

Stefanie Mangold, PhD, Senior Editor Journals Medicine \& Life Sciences

Stefanie.Mangold@springer.com

Submissions should be received by May 9th, 2022.

Publisher's note Springer Nature remains neutral with regard to jurisdictional claims in published maps and institutional affiliations. 